\title{
Effects of alcohols on the respiration and fermentation of aerated suspensions of baker's yeast
}

\author{
Helle N. Carlsen, ${ }^{*}$ Hans Degn and David Lloyd $\dagger$ \\ Institute of Biochemistry, Odense University, Campusvej 55, DK-5230 Odense M, Denmark
}

(Received 10 July 1991; accepted 5 September 1991)

\begin{abstract}
The immediate effects of externally added alcohols on $\mathrm{CO}_{2}$ production and $\mathrm{O}_{2}$ consumption of suspensions of washed, aerated baker's yeast were studied by stopped-flow membrane inlet mass spectrometry. Glucosesupported fermentation was progressively inhibited by increasing ethanol concentration $(0-20 \%, v / v)$. The inhibition by ethanol was quite different from that observed for acetaldehyde; thus it is unlikely that toxicity of the latter can account for the observed effects. For five different alkanols (methanol, ethanol, 1-propanol, 2-propanol and 1-butanol) increasing inhibition of anaerobic fermentation was correlated with increased partition coefficients into a hydrophobic milieu. This suggests that the action of ethanol is primarily located at a hydrophobic site, possibly at a membrane. Results for respiratory activities were not as definite as for those for anaerobic metabolism because some alkanols act as respiratory substrates as well as giving inhibitory effects.
\end{abstract}

\section{Introduction}

The accumulation of ethanol in cultures of yeast eventually leads to decreased rates of fermentation (production of ethanol and $\mathrm{CO}_{2}$ ), decreased growth rates and loss of viability (Ingram \& Buttke, 1984). Despite a great deal of research, it is still not clear exactly how ethanol inhibits various essential functions. Part of the difficulty in distinguishing mechanisms is due to the multiplicity of alcohol-sensitive sites.

Earlier claims that hexokinase and alcohol dehydrogenase are key sites for ethanol inhibition have been refuted by the detailed studies of Larue et al. (1984). However, competitive inhibition by ethanol of phosphoglycerate kinase, phosphoglycerate mutase and pyruvate decarboxylase, and non-competitive inhibition of the remaining nine enzymes clearly indicates a role for ethanol as an inhibitor of glycolysis (Millar et al., 1982).

Other observations indicate that interaction of ethanol with membranes is also involved in the inhibition of glycolysis. There are several reports describing the inhibitory effect of ethanol on transport of sugars and amino acids (Thomas \& Rose, 1979; Leao \& Van Uden, 1982; Iglesias et al., 1991). The inhibition pattern is noncompetitive, ethanol decreasing the maximal uptake rate. The correlation found between the hydrophobicity

$\dagger$ Present address: Microbiology Group (PABIO), University of Wales College of Cardiff, PO Box 915, Cardiff CF1 13TL, UK. and ability of alkanols to inhibit glucose utilization (Gray \& Sova, 1956; Ingram \& Buttke, 1984) and glucose uptake (Leao \& Van Uden, 1982) seems to indicate a membrane effect. Yeast grown in the presence of increasing concentrations of ethanol has also been shown to increase the content of mono-unsaturated fatty acids in its membrane lipids in response (Beavan et al., 1982). Non-specific effects due to reduced water activity and accumulation of toxic compounds such as acetaldehyde have also been proposed to be involved in inhibition by ethanol (Jones, 1989).

In this paper we report the early effects of added ethanol on $\mathrm{CO}_{2}$ production by suspensions of aerated non-proliferating baker's yeast. We show that both aerobic and anaerobic $\mathrm{CO}_{2}$ production from glucose is inhibited by ethanol and that increasing inhibitory effects of higher alkanols on $\mathrm{CO}_{2}$ production correlate with increasing hydrophobicity. Our results favour the assumption of a membrane effect in inhibition of yeast metabolism by ethanol.

\section{Methods}

Organism. The organism used was a commercial strain of baker's yeast (Saccharomyces cerevisiae) (Danske Spritfabrikker, Grenaa, Denmark). A suspension $(20 \%, \mathrm{w} / \mathrm{v})$ in $10 \mathrm{~mm}$-sodium citrate buffer, pH 4.4, was aerated vigorously ( 2 litres of air per litre of suspension per $\mathrm{min})$ at room temperature $\left(21^{\circ} \mathrm{C}\right)$ for at least $18 \mathrm{~h}$. The organisms were washed twice by centrifugation at $3000 \mathrm{~g}$ for $3 \mathrm{~min}$, and finally 


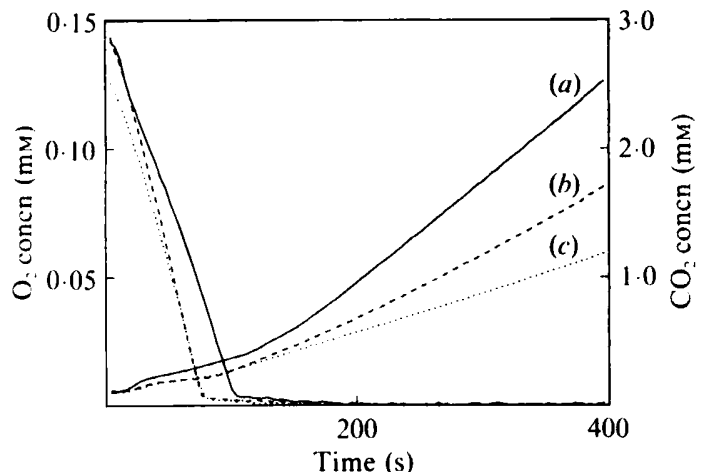

Fig. 1. Effects of ethanol on the rates of $\mathrm{O}_{2}$ consumption and $\mathrm{CO}_{2}$ production in a washed, aerated, non-proliferating suspension of baker's yeast after mixing with air-saturated glucose solution in a stopped flow cell. Time zero corresponds to cessation of the flow. The decreasing signals are $\mathrm{O}_{2}$ consumption and the increasing signals are $\mathrm{CO}_{2}$ production. Cell density was $5.5 \mathrm{mg}$ dry wt $\mathrm{ml}^{-1}$. The glucose concentration was $20 \mathrm{mM}$ and the ethanol concentrations $(\mathrm{v} / \mathrm{v})$ were $(a)$ $0 \%$, (b) $5 \%$ and (c) $10 \%$.

resuspended in the same buffer at a cell concentration of about $10 \mathrm{mg}$ dry wt $\mathrm{ml}^{-1}$

Measurements of $\mathrm{O}_{2}$ and $\mathrm{CO}_{2}$. Details of the method used for simultaneous monitoring of $\mathrm{O}_{2}$ and $\mathrm{CO}_{2}$ by stopped-flow membrane inlet mass spectrometry have been published previously (Degn \& Kristensen, 1986; Gaunt et al., 1988). Aerated yeast suspension and $40 \mathrm{~mm}$-glucose (both in $10 \mathrm{~mm}$-sodium citrate buffer, pH 4.4) were equilibrated at $30^{\circ} \mathrm{C}$. Equal volumes of the two components were drawn into the reaction vessel of the mass spectrometer (VG Gas Analysis, UK). After arrest of the flow, effected by a magnetic valve, $\mathrm{O}_{2}$ consumption and $\mathrm{CO}_{2}$ evolution were monitored through a Teflon membrane ( $12 \mu \mathrm{m}$ thick; Radiometer, Denmark) at $\mathrm{m} / \mathrm{z}$ values 32 and 44 respectively. Calibration for $\mathrm{O}_{2}$ was with air-saturated buffer. That for $\mathrm{CO}_{2}$ employed standard gas mixtures or mixing $400 \mu \mathrm{m}-\mathrm{NaHCO}_{3}$ with sodium citrate buffer ( $\mathrm{pH} 4.4$ ). Solubilities used for $\mathrm{O}_{2}$ in airsaturated buffer and for $\mathrm{CO}_{2}$ at $30^{\circ} \mathrm{C}$ were $247 \mu \mathrm{M}$ and $29.7 \mathrm{~mm}$ respectively in the absence of ethanol (Wilhelm et al., 1977). For correction purposes the small consumption of gases by the measuring device was determined by monitoring the gases in citrate buffer in the absence of yeast.

\section{Results}

The early stages of the metabolism of glucose by washed, aerated, non-proliferating suspensions of baker's yeast are shown in Fig. 1 (curve $a$ ). In the absence of added ethanol, the rate of $\mathrm{O}_{2}$ consumption accelerated gradually over the first $80 \mathrm{~s}$. Aerobic $\mathrm{CO}_{2}$ production also showed a gradual acceleration corresponding with that of $\mathrm{O}_{2}$ utilization, but as $\mathrm{O}_{2}$ became limiting, it underwent a rapid phase of increase to reach constant velocity after about $200 \mathrm{~s}$. When the experiment was repeated in the presence of $5 \%(\mathrm{v} / \mathrm{v})$ ethanol, the respiration rate of the organisms increased (Fig. 1, curve $b$ ), but aerobic $\mathrm{CO}_{2}$ evolution was markedly inhibited. Exhaustion of $\mathrm{O}_{2}$ was
Table 1. Effects of ethanol on $\mathrm{O}_{2}$ consumption and aerobic and anaerobic $\mathrm{CO}_{2}$ production in baker's yeast

Mass spectrometric determinations typical of results obtained with three different yeast suspensions are shown. Values for the degree of inhibition $(-)$ or stimulation $(+)$ are given in parentheses.

\begin{tabular}{|c|c|c|c|c|}
\hline \multirow{2}{*}{\multicolumn{2}{|c|}{ Addition }} & \multicolumn{2}{|c|}{ Aerobic } & \multirow{3}{*}{$\frac{\text { Anaerobic }}{\left[\begin{array}{c}V_{\mathrm{CO}_{2}} \\
\left(\mathrm{nmol} \mathrm{CO}_{2} \mathrm{~min}^{-1}\right. \\
\left.(\mathrm{mg} \text { dry } \mathrm{wt})^{-1}\right]\end{array}\right.}$} \\
\hline & & \multirow{2}{*}{\multicolumn{2}{|c|}{$\underset{\left.(\mathrm{mg} \text { dry } w t)^{-1}\right]}{V_{\mathrm{O}_{2}}} \underset{\left.(\mathrm{mg} \text { dry } w)^{-1}\right]}{V_{\mathrm{CO}_{2}}}$}} & \\
\hline $\begin{array}{l}\text { Ethanol } \\
(\%, v / v)\end{array}$ & $\begin{array}{l}\text { Glucose } \\
(\mathrm{mM})\end{array}$ & & & \\
\hline 0 & 20 & 32 & 48 & 172 \\
\hline $2 \cdot 5$ & 20 & $46(+44 \%)$ & $25(-48 \%)$ & $146(-15 \%)$ \\
\hline $5 \cdot 0$ & 20 & $40(+25 \%)$ & $24(-50 \%)$ & $110(-36 \%)$ \\
\hline 10 & 20 & $39(+22 \%)$ & $23(-52 \%)$ & $60(-65 \%)$ \\
\hline 0 & 0 & $0 \cdot 4$ & $2 \cdot 4$ & $1 \cdot 2$ \\
\hline 5 & 0 & 36 & $2 \cdot 6$ & $4 \cdot 2$ \\
\hline 10 & 0 & 38 & 4.5 & 6.5 \\
\hline 20 & 0 & 64 & $4 \cdot 7$ & $7 \cdot 5$ \\
\hline 25 & 0 & 41 & $8 \cdot 6$ & $9 \cdot 5$ \\
\hline 30 & 0 & 22 & $4 \cdot 3$ & 6.9 \\
\hline
\end{tabular}

again accompanied by accelerated $\mathrm{CO}_{2}$ production. The phase of constant anaerobic fermentation eventually attained (after about $200 \mathrm{~s}$ ) also showed inhibition by comparison with the control rate in the absence of ethanol. When higher concentrations of ethanol were used (e.g. $10 \%$; Fig. 1, curve $c$ ) effects on aerobic $\mathrm{O}_{2}$ consumption were similar to those with $5 \%(\mathrm{v} / \mathrm{v})$ ethanol. Aerobic $\mathrm{CO}_{2}$ production was nearly the same, but anaerobic $\mathrm{CO}_{2}$ evolution was further inhibited. In these experiments glucose and ethanol were presented simultaneously to the organisms. Pre-incubation of organisms with glucose gave some 'protection' against the effects of ethanol, so that somewhat lower figures for inhibition were obtained (not shown). However, the overall pattern of effects remained similar. Experiments done in the absence of glucose indicated that at low concentrations (e.g. $10 \%$ ) ethanol was a respiratory substrate. At higher concentrations ethanol $(>20 \%)$ became inhibitory to $\mathrm{O}_{2}$ consumption. Anaerobic $\mathrm{CO}_{2}$ production progressively increased as the ethanol concentration was increased. These results are summarized in Table 1 .

Acetaldehyde $(12.5 \mathrm{mM})$ was a potent inhibitor of glucose-supported respiration, as shown by marked decreases in $\mathrm{O}_{2}$ consumption. Aerobic and anaerobic $\mathrm{CO}_{2}$ production was only marginally decreased (by a few per cent). At $125 \mathrm{~mm}$-acetaldehyde, inhibition of both glucose respiration and fermentation was observed; $\mathrm{O}_{2}$ consumption and $\mathrm{CO}_{2}$ production of the starved yeast in the absence of glucose was stimulated by acetaldehyde (Table 2).

In order to determine whether the effects of ethanol can be modified by the long-term exposure of non- 
Table 2. Effects of acetaldehyde on $\mathrm{O}_{2}$ consumption and aerobic and anaerobic $\mathrm{CO}_{2}$ production in baker's yeast

Mass spectrometric determinations typical of results obtained with three different yeast suspensions are shown. Values for the degree of inhibition (-) are given in parentheses.

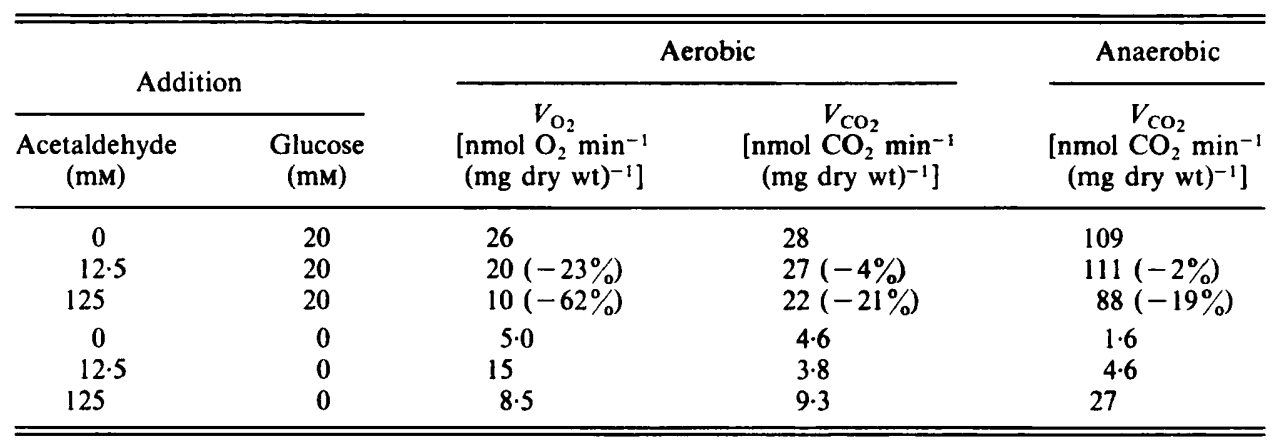

Table 3. Effects of alkanols on glucose-supported respiration and $\mathrm{CO}_{2}$ production by non-proliferating suspensions of baker's yeast

Mass spectrometric determinations typical of results obtained with two different yeast suspensions are shown. The concentration of glucose was $20 \mathrm{~mm}$ in all experiments. Values are presented as percentages of the rates of respiration or $\mathrm{CO}_{2}$ production when no alkanol was added $\left[V_{\mathrm{O}_{2}}=28 \mathrm{nmol} \mathrm{O}_{2} \min ^{-1}(\mathrm{mg} \text { dry wt) })^{-1}\right.$; aerobic $V_{\mathrm{CO}_{3}}=44 \mathrm{nmol} \mathrm{CO} \mathrm{min}^{-1}(\mathrm{mg} \text { dry wt })^{-1}$; anaerobic $\left.V_{\mathrm{CO}_{2}}=136 \mathrm{nmol} \mathrm{CO} \mathrm{min}^{-1}(\mathrm{mg} \text { dry wt })^{-1}\right]$. +, Stimulation; - , inhibition.

\begin{tabular}{lcccc}
\hline \hline \multirow{2}{*}{$\begin{array}{l}\text { Alkanol } \\
\text { added }\end{array}$} & $\begin{array}{c}\text { Concn } \\
(\mathrm{M})\end{array}$ & $\begin{array}{c}V_{\mathrm{O}_{2}} \\
\mathbf{( \% )}\end{array}$ & $\begin{array}{c}V_{\mathrm{CO}_{2}} \\
(\%)\end{array}$ & $\begin{array}{c}V_{\mathrm{CO}_{2}} \\
(\%)\end{array}$ \\
\hline Methanol & 2.50 & -6 & -24 & -20 \\
Ethanol & 0.86 & +36 & -91 & -25 \\
& 1.72 & +36 & -86 & -56 \\
1-Propanol & 0.67 & +30 & -67 & -37 \\
& 1.33 & +49 & -28 & -70 \\
2-Propanol & 0.66 & -6 & -32 & -23 \\
& 1.31 & -6 & -32 & -68 \\
1-Butanol & 0.55 & +21 & -28 & -55 \\
& 1.09 & -37 & -51 & -81 \\
Isobutanol & 0.27 & -20 & -21 & -30 \\
& 0.54 & -41 & -32 & -53 \\
\hline \hline
\end{tabular}

proliferating organisms, another series of experiments used yeast that had been starved in the usual way $(18 \mathrm{~h}$ aeration), but was then aerated for $4 \mathrm{~h}$ in the presence of either $5 \%$ or $20 \%$ ethanol. Essentially similar results were obtained irrespective of pretreatment. Thus addition of $10 \%$ ethanol accelerated respiration and gave extensive inhibition of both aerobic and anaerobic $\mathrm{CO}_{2}$ evolution; $20 \%$ ethanol gave some relief of the inhibition of aerobic $\mathrm{CO}_{2}$ production but in other respects was more inhibitory (data not shown).

Table 3 shows the effects of various alkanols on the metabolism of baker's yeast. Methanol was less inhibi-

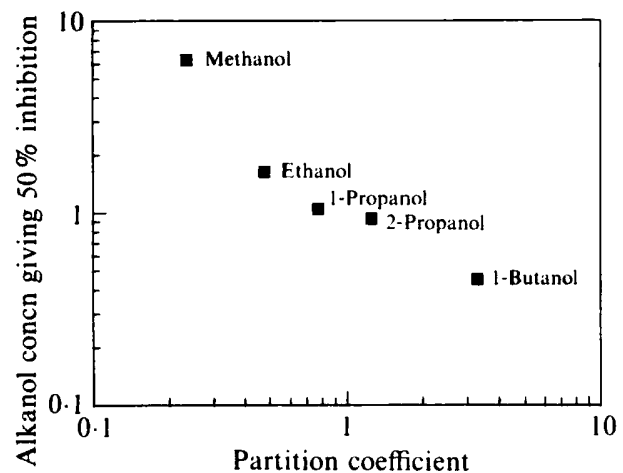

Fig. 2. Inhibition of anaerobic $\mathrm{CO}_{2}$ production by various alkanols as a function of their partition coefficient. Anaerobic $\mathrm{CO}_{2}$ production was measured as described in Fig. 1 in the presence of different concentrations of various alkanols, and the alkanol concentration that gave $50 \%$ inhibition of anaerobic $\mathrm{CO}_{2}$ production was calculated. The logarithm of this concentration was plotted against the logarithm of the partition coefficient of the alkanol in the dimyristoyl lecithin/water system (Katz \& Diamond, 1974).

tory than ethanol towards anaerobic $\mathrm{CO}_{2}$ production whereas higher alkanols were more inhibitory. When the logarithm of the alkanol concentration giving $50 \%$ inhibition of anaerobic $\mathrm{CO}_{2}$ output was plotted against the logarithm of its partition coefficient between dimyristoyl lecithin and water (Katz \& Diamond, 1974) a good correlation was obtained (Fig. 2). This relationship could not be established for respiratory functions where the effects of higher alkanols were more complex (Table 3).

\section{Discussion}

Whereas measurements of glucose uptake were used in previous studies of the effect of ethanol on yeast 
metabolism, we based the present study on measurements of $\mathrm{CO}_{2}$ production. The onset of the inhibitory effects of ethanol on aerobic and anaerobic $\mathrm{CO}_{2}$ production by intact non-proliferating cell suspensions of baker's yeast were rapid, occurring in less than $10 \mathrm{~s}$. Utilization of ethanol as a mitochondrial respiratory substrate (Ohnishi et al., 1966; Lloyd, 1974) masks possible inhibitory effects when measured by $\mathrm{O}_{2}$ consumption and aerobic $\mathrm{CO}_{2}$ production. As anaerobic $\mathrm{CO}_{2}$ production is a result of glycolysis it is a direct measure of the fermentation rate.

The degree of inhibition of anaerobic $\mathrm{CO}_{2}$ production was linear with ethanol concentration up to $10 \%$ ethanol and it was not qualitatively altered by previous exposure to ethanol for $4 \mathrm{~h}$. The concentration of ethanol which reduced the fermentative activity by $50 \%$ was found, in our experiments, to be $8-10 \%$. For baker's yeast Kalmokoff \& Ingledew (1985) found 50\% inhibition of fermentation at $13 \%$ ethanol. Growth was totally inhibited at $12 \%$ ethanol and the minimum level of ethanol at which losses in viability were detected was $18 \%$. Their data indicate that fermentation ability is affected at a much lower ethanol concentration than viability. Decreased viability seems therefore not to be the cause of the observed inhibition of fermentation.

A number of mechanisms have been proposed to be involved in ethanol inhibition. These include alteration of membrane permeability properties, sugar transport systems, direct effects on enzymes, product inhibition or accumulation of toxic metabolites (Leao \& Van Uden, 1982; Ingram \& Buttke, 1984; Casey \& Ingledew, 1986; Jones \& Greenfield, 1987; Jones, 1989; Koukou et al., 1990; D'Amore \& Stewart, 1990). These various proposals are not mutually exclusive, and different inhibitory effects may assume greater or lesser significance in different yeasts and under different environmental situations.

That acetaldehyde $(12.5 \mathrm{~mm})$ gives a completely different pattern of effects from those shown by ethanol strongly indicates that the accumulation of this substrate cannot account for ethanol inhibition of baker's yeast, even though this has been claimed to be the case in some other strains of $S$. cerevisiae (Jones, 1989). Thus, in our experiments, acetaldehyde is a more powerful inhibitor of respiration than of anaerobic glycolysis, whereas ethanol has a much more pronounced effect on anaerobic $\mathrm{CO}_{2}$ production.

The striking correlation between hydrophobicity within the alkanol series and inhibition of anaerobic glycolytic $\mathrm{CO}_{2}$ production provides a strong indication that hydrophobic site(s) are the main target for the ethanol inhibition. At present it is not possible to decide whether interaction of ethanol with hydrophobic sites on, for example, the glycolytic enzymes or on a membrane is the cause of decreased fermentation. Ethanol inhibition of glucose uptake, as observed by Leao \& Van Uden (1982), could account for inhibition of fermentation by ethanol if glucose transport is ratelimiting for glycolysis. Leao \& Van Uden (1982) found that the ethanol concentration resulting in $50 \%$ inhibition of the glucose uptake rate was $1 \cdot 1 \mathrm{M}(6 \cdot 3 \%, \mathrm{v} / \mathrm{v})$. This value is in the same range as the ethanol concentration which, in our experiments resulted in $50 \%$ inhibition of glycolytic $\mathrm{CO}_{2}$ production.

This work was supported by the Centre for Food and Process Biotechnology, The Technical University, Copenhagen, Denmark.

\section{References}

Beavan, M. J., Charpentier, C. \& Rose, A. H. (1982). Production and tolerance of ethanol in relation to phospholipid fatty acyl composition in Saccharomyces cerevisiae NCYC 431. Journal of General Microbiology 128, 1447-1455.

CASEY, G. P. \& INGLEDEW, W. M. (1986). Ethanol tolerance in yeasts. Critical Reviews in Microbiology 13, 219-280.

D'AMORE, T. \& Stewart, G. G. (1990). A study of ethanol tolerance of yeast. Critical Reviews in Biotechnology 9, 287-304.

DEGN, H. \& KRISTENSEN, B. (1986). Stopped flow mass spectrometry: applications to the carbonic anhydrase reaction. Journal of Biochemical and Biophysical Methods 12, 305-310.

GAUNT, D. M., DEGN, H. \& LLOYD, D. (1988). The influence of oxygen and organic hydrogen acceptors on glycolytic carbon dioxide production in Brettanomyces anomalous. Yeast 4, 249-255.

GraY, W. D. \& Sova, C. (1956). Relation of molecule size and structure to alcohol inhibition of glucose utilization by yeast. Journal of Bacteriology 72, 349-356.

Iglesias, R., Ferreas, J. M., Arias, F. J., Muñoz, R. \& Girbés, T. (1991). Effect of continued exposition to ethanol on activity of the ammonium and fructose transport systems in Saccharomyces cerevisiae var. ellipsoideus. Biotechnology and Bioengineering 37, 389391.

INGRAM, L. O. \& BUTTKE, T. M. (1984). Effects of alcohols on microorganisms. Advances in Microbial Physiology 25, 253-300.

JONES, R. P. (1989). Biological principles for the effects of ethanol. Enzyme and Microbial Technology 11, 130-153.

Jones, R. P. \& Greenfield, P. F. (1987). Specific and non-specific inhibitory effects of ethanol on yeast growth. Enzyme and Microbial Technology 9, 334-338.

KALMOKOFF, M. L. \& INGLEDEW, W. M. (1985). Evaluation of ethanol tolerance in selected Saccharomyces strains. Journal of the American Society of Brewing Chemists 43, 189-196.

KATZ, Y. \& DIAMOND, J. M. (1974). Thermodynamic constants for nonelectrolyte partition between dimyristoyl lecithin and water. Journal of Membrane Biology 17, 101-120.

Koukou, A. I., Tsoukatos, D. \& Drainas, C. (1990). Effects of ethanol on the phospholipid and fatty acid content of Schizosaccharomyces pombe membranes. Journal of General Microbiology 136, 12711277.

Larue, F., Lafon-Lafourcade, S. \& Ribereau-Gayon, P. (1984). Relationship between the inhibition of alcoholic fermentation by Saccharomyces cerevisiae and the activities of hexokinase and alcohol dehydrogenase. Biotechnology Letters 6, 687-692.

LEAO, C. \& VAN UDEN, N. (1982). Effect of ethanol and other alkanols on the glucose transport system of Saccharomyces cerevisiae. Biotechnology and Bioengineering 24, 2601-2604.

LLOYD, D. (1974). The Mitochondria of Microorganisms, p. 101, London: Academic Press.

Millar, D. G., Griffiths-Smith, K., Algar, E. \& Scopes, R. K. (1982). Activity and stability of glycolytic enzymes in the presence of ethanol. Biotechnology Letters 4, 601-606. 
Ohnishi, T., Kawaguchi, K. \& Hagihara, B. (1966). Preparation and some properties of yeast mitochondria. Journal of Biological Chemistry 241, 1797-1806.

Thomas, D. S. \& Rose, A. H. (1979). Inhibitory effect of ethanol on growth and solute accumulation by Saccharomyces cerevisiae as affected by plasma-membrane lipid composition. Archives of Microbiology 122, 49-55.

Wilhelm, E., Battino, R. \& Wilcock, R. J. (1977). Low-pressure solubility of gases in liquid water. Chemical Reviews 77, 219-262. 